
\title{
$\angle S$ Research Square \\ Age-structured Impact of Mitigation Strategies on COVID-19 Severity and Deaths in Kenya
}

Samuel Mwalili ( $\nabla$ smusili@jkuat.ac.ke)

Jomo Kenyatta University of Agriculture and Technology https://orcid.org/0000-0002-9703-6514

Mark E. M. Kimathi

Machakos University

Viona N. Ojiambo

Jomo Kenyatta University of Agriculture and Technology

Duncan K. Gathungu

Jomo Kenyatta University of Agriculture and Technology

Thomas N. O. Achia

University of the Witwatersrand

Research article

Keywords: Age structured, Non-pharmaceutical interventions, COVID-19, Mathematical model, Severity, Kenya pandemic

Posted Date: November 17th, 2020

DOI: https://doi.org/10.21203/rs.3.rs-105797/v1

License: (c) (i) This work is licensed under a Creative Commons Attribution 4.0 International License. Read Full License 


\section{Abstract}

Introduction: COVID-19, a coronavirus disease 2019, is an ongoing pandemic caused by severe acute respiratory syndrome coronavirus 2 (SARS-CoV-2). There have been a lot of attempts to model this pandemic from a global perspective. The Novel Coronavirus is still spreading quickly in several countries and the peak has not yet been reached in many countries. We developed age-structured model for describing the COVID-19 pandemic in Kenya under different non-pharmaceutical interventions. The first case in Kenya was identified in March 13, 2020 with the pandemic increasing to 465 confirmed cases by end of $3^{\text {rd }}$ May, 2020. We fitted an age-structured deterministic mathematical model in Kenyan context.

Methods: We model the COVID-19 situation in Kenya using Age-structured Susceptible Exposed Infectious Recovered compartmental model. These compartments follow a cascade of the disease from the Susceptible to Exposed individuals who in return are either symptomatic or asymptomatic. The symptomatic depict mild signs, which can develop to severe symptoms warranting hospitalization or can otherwise recover. The severe cases can recover with some developing critical condition. The critical are admitted at intensive care units. The resulting age-dependent ordinary differential equations from the model are solved using fourth order Runge-Kutta methods. We controlled for school closure, social distancing and lockdown in terms of movement restrictions

Results: The model shows varying epidemic peak by age-structure and the mitigation scenarios. The peak dates for unmitigated (UM), the 45\% NPI (M45) and School closure-curfew-partial lockdown NPI (SCL) are May $21^{\text {st }}$, October $17^{\text {th }}$ and December $13^{\text {th }} 2020$, respectively. Their respective cumulative infections peaks are $43 \mathrm{M}, 24 \mathrm{M}$ and $25 \mathrm{M}$. The daily reported severe cases, critical cases and death proportionately increased with age.

Conclusions: The cumulative number of infections reduces greatly with introduction of school closure, social distancing and restricted movement in highly affected counties. The degree of COVID-19 severity increases with age. However, it is not immediately clear when these restrictions can be lifted.

\section{Introduction}

Coronavirus pandemic is an ongoing pandemic of coronavirus disease 2019 (COVID-19) caused by severe acute respiratory syndrome coronavirus 2 (SARS-CoV-2). The first reported case was in mainland China, City of Wuhan, Hubei on the 29th of December 2019 [1]. The disease quickly expanded into an epidemic in Wuhan and elsewhere in China, with subsequent spread to multiple countries resulting in the World Health Organization (WHO) declaring it as a Public Health Emergency of International Concern (PHEIC) ON 30th January 2020 [2]. As of 25th April 2020 there were over two million infections globally, with the European region taking lead in these infections [3]. Case reports were not initially seen in Africa, but after the first case reported in Egypt followed by Algeria [4] cases quickly climbed in South Africa and Nigeria, though not at the pace seen during early epidemics in Europe and Asia. The first case reported in Kenya was on the 13th of March [5] in a traveler returning from the US via the UK, and by 6th October 2020 there were 39,449 confirmed cases, with the greatest concentration of cases in the two largest cities in Kenya, Nairobi and Mombasa. 
SARS-CoV-2 is primarily transmitted through direct and indirect physical contact. In direct physical contact there occurs physical contact between an infected person and a susceptible person through respiratory droplets produced by an infected person who is either sneezing or coughing. Whereas in indirect physical contact, transmission occurs when susceptible persons touch contaminated surfaces. contact routes [3], [6][9]. Based on currently available information and clinical expertise, older adults and people of any age with serious underlying medical conditions might be at higher risk for severe illness from COVID-19 [1], [10]. This motivates the need for age-structure consideration in the analysis of COVID-19 pandemic.

Infection can be categorized as asymptomatic (sub-clinical) or symptomatic. The incubation period for COVID-19, which is the time between exposure to the virus (becoming infected) and symptom onset, is on average 5-6 days, however it can be up to 14 days [11]-[15]. It is now known that some infected persons can be contagious prior to symptom onset, resulting in pre-symptomatic transmission among those who will eventually present symptoms. Asymptomatic transmission refers to transmission of the virus from a person who never develops symptoms [2], and is currently poorly understood both in terms of the proportion of cases that are asymptomatic and their relative infectiousness compared with symptomatic disease, though there is evidence that symptomatic illness is more common in older cases [5], and investigators have used models based on cases in Wuhan to show that the majority of infections are likely asymptomatic, especially in the young [5] time from symptom onset to hospitalization is likely dependent on available medical resources and care seeking behaviors, but studies $[12,16-18]$ have found that the median time from onset of symptoms to first hospital admission was $7 \cdot 0$ days, to shortness of breath was 8.0 days, to Acute Respiratory Distress Syndrome (ARDS) was 9.0 days, to mechanical ventilation was 10.5 days and to ICU admission was 10.5 days. Further, mortality rate depends on the severity of the disease.

The modeling of infectious diseases has become paramount in studying the disease transmission dynamics $[26,35]$. It is can be used to predict the future course of an outbreak and to evaluate strategies that can effectively control an epidemic. Mathematical models have been used to describe the transmission dynamics and the spread of the COVID-19 across the population [5], [6], [16]-[19]. These models are either deterministic, where there is only one exact solution, or stochastic where there is a range of solutions. The degree of the pandemic is typically presented by basic reproductive number (R0), which is defined as the average number of secondary infections produced by a typical case of an infection in a population where everyone is susceptible [20]-[25]. This is affected by the rate of contacts in the host population, the probability of infection being transmitted during contact and the duration of infectiousness. The basic reproductive number of a disease cannot be measured directly and must be estimated from disease transmission models. One previous study for COVID-19 in Kenya estimated that R0 ranges from $1.78(95 \% \mathrm{Cl}$ $1.44-2.14)$ to $3.46(95 \% \mathrm{Cl} 2.81-4.17)[5]$.

With the emergence of the COVID-19 pandemic several models have been developed to assess the impact of various intervention measures $[5,6,10,19-22,29,30]$. SEIR models are primarily used in modelling diseases because of their simplicity in providing the dynamics of a disease using compartments. A plausible SEIR mathematical prediction model can assist in determining suitable Non-pharmaceutical Intervention (NPIs) for COVID-19. In the absence of an available vaccine, NPIs have a strong potential to reduce the magnitude 
of the epidemic peak of COVID-19 and lead to a smaller number of overall cases by reducing the reproductive number (R0). This is because the attack rate of COVID-19 is influenced by the value of R0.

Social distancing has emerged as the most reliable NPI for the mitigation and control of COVID-19 [17], [26][29]. Reduction of social contacts in schools, workplaces, hospitals, markets amongst other public places are the main targets for achieving social distancing. Contact rates are heavily influenced by age, and rates of contacts within and between age groups are influenced by social structure and mixing patterns, and their inclusion in epidemic models can increase the model's realism [19], [26], [30]. Suppression, which aims at reversing the epidemic growth by driving the reproductive ratio below one, could help in lowering and flattening of the epidemic peak, thereby reducing the acute pressure on the health-care system. However, premature and sudden lifting of NPIs could lead to an earlier secondary peak, which could be flattened by relaxing the interventions intermittently $[26,35]$. A previous study in Kenya also predicted the risk of epidemic rebound after the social distancing measures are lifted prematurely [5].

In this study we assess the dynamics of an age-structured SEIR mathematical model that examines the impact of NPIs in curbing COVID-19 severity and death in Kenya is developed with an aim of achieving the following; (i)assessing the impact of suppression of social contacts on different age-groups, (ii)examine the age and social contact structures impact on the non-pharmaceutical interventions (iii) project the peak and end of the pandemic in Kenya the trend in the cumulative and reported infections,(iv)provide plausible periods and gradual procedures for lifting of the NPIs. The study is also a working tool for policy formulation that will enable Kenya to delay and eventually flatten the epidemic peak. The epidemiological model used is the usual SEIR model stratified for predicting severe and critical cases that is further stratified into different age groups because of their effect on mixing patterns and social structures.

\section{Methods}

We used a Susceptible-Exposed-Infectious-Recovered (SEIR) model stratified by four age groups ( $0-15$ years, 15-29 years, 30-59 years and 60 + years). The choice of these age groups was informed by age grouping from the Kenya's Ministry of Health $(\mathrm{MOH})$ reports. The SEIR model determines the flow of individuals between four phases: susceptible (S), exposed (E), infected (I), and recovered or removed (R). The SEIR model governs how fast individuals move from being susceptible to exposed, from exposed to infected, and from infected to recovered.

In this case, the infectious class is broken into Asymptomatic (A) and Mild (M) symptomatic cases. The mild symptomatic cases can then progress to severe cases $(H)$ that are hospitalized, who in turn may progress to critical (C) who require ventilators and specialized treatment in ICU. Mild, severe and critical can all progress to the recovery compartment $(\mathrm{R})$, while those in critical state can also die. This model is represented schematically by Fig. 1 .

The model makes the following assumptions:

a) The disease is transmitted through human-human transmissions. 
b) There is no reservoir for indirect physical transmission. There is no cross-infection occurring from neither pathogen in the environment (reservoir) nor human-animal transmissions.

c) Susceptible individuals (S) are exposed or infected through contact with infectious individuals. At the beginning of the epidemic, each infectious individual cause on average R0 secondary infections.

d) After an average incubation period of 5 days, exposed individuals (E) either become asymptomatic (A) or exhibit mild symptomatic infections (M).

e) The virus-infected person is not infectious during the incubation period.

f) Mild infectious individuals $(M)$ either recover $(R)$ or progress to severe disease $(H)$. The ratio of recovery to severe progression depends on age;

g) Severely sick individuals $(\mathrm{H})$ either recover $(\mathrm{R})$ or deteriorate and turn critical $(\mathrm{C})$. Again, this is age dependent;

h) Critically ill (C) individuals either return to severe status (H) or die (D).

i) Recovered individuals (R) cannot be infected again.

The ordinary differential equations (ODE) resulting from these compartments are solved using a combination of fourth and fifth order Runga-Kutta method [31]. This is implemented in Matlab version 15 [32] and Matlab ODE suite [33].

The list of parameters used in the model is shown in Table 1. These parameters are based on literature [5] and national consensus.

Table 1

List of the parameters used in the SEIR model 


\begin{tabular}{|l|l|c|c|c|c|c|}
\hline Model Parameters & $\begin{array}{l}\text { Sym } \\
\text { bol }\end{array}$ & $\begin{array}{l}<\mathbf{1 5} \\
\text { years }\end{array}$ & $\begin{array}{l}\mathbf{1 5 - 2 9} \\
\text { years }\end{array}$ & $\begin{array}{l}\mathbf{3 0 - 5 9} \\
\text { years }\end{array}$ & $\begin{array}{l}\mathbf{5 9 +} \\
\text { years }\end{array}$ & $\begin{array}{l}\text { Aver } \\
\text { age }\end{array}$ \\
\hline Proportion of Asymptomatic cases & $\theta_{a}$ & 0.85 & 0.8 & 0.75 & 0.7 & $\mathbf{0 . 7 7 5}$ \\
\hline $\begin{array}{l}\text { Proportion of Mild cases (M) that } \\
\text { progress to Severe cases (H) }\end{array}$ & $\kappa_{a}$ & 0.10 & 0.11 & 0.12 & 0.13 & $\mathbf{0 . 1 1 5}$ \\
\hline $\begin{array}{l}\text { Proportion of Severe cases (H) that } \\
\text { progress to Critical cases (C) }\end{array}$ & $\xi_{a}$ & 0.05 & 0.10 & 0.15 & 0.2 & $\mathbf{0 . 1 2 5}$ \\
\hline $\begin{array}{l}\text { Proportion of the Critical cases (C) that } \\
\text { progress back to Severe cases (H) }\end{array}$ & $\emptyset_{a}$ & 0.5 & 0.45 & 0.4 & 0.35 & $\mathbf{0 . 4 2 5}$ \\
\hline $\begin{array}{l}\text { Reciprocal of the average incubation } \\
\text { period }\end{array}$ & $\omega$ & 0.2 & 0.2 & 0.2 & 0.2 & $\mathbf{0 . 2}$ \\
\hline $\begin{array}{l}\text { Recovery proportion of Asymptomatic } \\
\text { cases (A) }\end{array}$ & $\gamma_{A_{a}}$ & 1 & 1 & 1 & 1 & $\mathbf{1}$ \\
\hline $\begin{array}{l}\text { Recovery proportion of Severe cases } \\
\text { (H) }\end{array}$ & $\gamma_{H_{a}}$ & 0.95 & 0.90 & 0.85 & 0.80 & $\mathbf{0 . 8 7 5}$ \\
\hline Recovery proportion of Mild cases (M) & $\gamma_{M_{a}}$ & 0.9 & 0.89 & 0.88 & 0.87 & $\mathbf{0 . 8 8 5}$ \\
\hline $\begin{array}{l}\text { Proportion of fatalities of Critical cases } \\
\text { (C) }\end{array}$ & $\lambda_{a}$ & 0.50 & 0.55 & 0.60 & 0.65 & $\mathbf{0 . 5 7 5}$ \\
\hline
\end{tabular}

The age distribution by sex in Kenyan population from the 2019 Census [34] is shown in the population pyramid in Fig. 2. As can be seen majority of the Kenyan population are young with a median age of $\mathrm{X}$. The proportions in age group are 39\% (0-15 years), 28\% (15-29 years), 28\% (30-59 years) and 5\% (60+years).

In addition to unmitigated (UM) scenario that assumed $25 \%$ reduction in contacts rate, we considered the impact of two different non-pharmaceutical interventions (NPI) implemented individually, namely:

a) Overall reduction $45 \%$ of contacts (M45) NPI. In M45 NPI, the contacts workplaces, household and others are reduced by $45 \%$; and

b) School closure, curfew and partial lockdown (SCL) NPI. The SCL NPI takes $100 \%$ reduction in school contacts, for curfew we reduce contacts by $30 \%$ in both workplaces and other places, and for partial Lockdown we take $45 \%$ reduction of contacts in both workplaces and other places and $25 \%$ increase in household contacts.

The contact matrix were computed using [35] methods. Figure 3 shows the contact matrix for Kenya for each NPI.

\section{Results}

We compare the unmitigated scenario with the two non-pharmaceutical interventions on the daily reported severe cases. As can be seen in Fig. 4 the severe cases in the unmitigated scenario peaks quite early, on the 
22nd May 2020 day from when the first case was reported, with the peaks of the two NPI occurring on 22nd October and 5th October 2020 respectively. Thus, the NPIs result in delayed peaks that gives the ministry of health extra more time for planning the health response system.

We also assess the impact of the age-structure on non-pharmaceutical interventions by looking at the number of daily reported critical cases and deaths under the SCL NPI. The majority of the critical cases and deaths are occurring at ages 30-59 followed by 15-29. Despite the low population size the number of critical cases and deaths in ages $60+$ years matches the below 15 years which has the highest population density.

The effects of NPIs are clearly demonstrated in Table 2. It is immediately clear that NPIs result in longer peak days, reduced number of reported cases at peak time and reduced peak at the end of the epidemic. Many more deaths will be averted by the two NPIs.

Table 2

Date of peak and peak of the daily cases as well as the peak and epidemic end of the cumulative cases\#

\begin{tabular}{|c|c|c|c|c|c|c|c|}
\hline Intervention & $\begin{array}{l}\text { Date of } \\
\text { peak }\end{array}$ & & $\begin{array}{l}\text { Number of } \\
\text { infections }\end{array}$ & $\begin{array}{l}\text { Number } \\
\text { of mild } \\
\text { cases }\end{array}$ & $\begin{array}{l}\text { Number } \\
\text { of Severe } \\
\text { cases }\end{array}$ & $\begin{array}{l}\text { Number } \\
\text { of Critical } \\
\text { cases }\end{array}$ & $\begin{array}{l}\text { Number } \\
\text { of Deaths }\end{array}$ \\
\hline \multirow[t]{3}{*}{ UM } & $\begin{array}{l}\text { 22nd } \\
\text { May } \\
2020\end{array}$ & Daily peak & $1,857,220$ & 414,173 & 136,221 & 65,555 & 52,444 \\
\hline & & $\begin{array}{l}\text { Cumulative } \\
\text { at peak }\end{array}$ & $19,506,003$ & $4,353,326$ & $1,307,517$ & 587,003 & 469,602 \\
\hline & & $\begin{array}{l}\text { Cumulative } \\
\text { epidemic } \\
\text { end }\end{array}$ & $42,879,732$ & $9,560,232$ & $3,239,855$ & $1,619,928$ & $1,295,942$ \\
\hline \multirow[t]{3}{*}{ M45 } & $\begin{array}{l}\text { 22nd } \\
\text { October } \\
2020\end{array}$ & Daily peak & 336,074 & 73,367 & 8,891 & 1,107 & 637 \\
\hline & & $\begin{array}{l}\text { Cumulative } \\
\text { at peak }\end{array}$ & $11,762,253$ & $2,570,250$ & 302,267 & 36,674 & 21,088 \\
\hline & & $\begin{array}{l}\text { Cumulative } \\
\text { epidemic } \\
\text { end }\end{array}$ & $24,061,139$ & $5,252,298$ & 637,880 & 79,732 & 45,846 \\
\hline \multirow[t]{3}{*}{ SCL } & $\begin{array}{l}\text { 5th } \\
\text { October } \\
2020\end{array}$ & Daily peak & 349,819 & 66,842 & 7,771 & 858 & 499 \\
\hline & & $\begin{array}{l}\text { Cumulative } \\
\text { at peak }\end{array}$ & $11,873,988$ & $1,405,288$ & 162,919 & 27,152 & 15,836 \\
\hline & & $\begin{array}{l}\text { Cumulative } \\
\text { epidemic } \\
\text { end }\end{array}$ & $24,574,982$ & $4,741,638$ & 556,187 & 63,143 & 36,834 \\
\hline
\end{tabular}




\section{Discussion}

The non-pharmaceutical interventions (NPIs) delayed the peak of the infections by five to seven months due to reduced generational contacts. Thereby the number of severe and critical cases are also minimal compared to the situation where there is minimal or no intervention. Consequently, the numbers of deaths are also reduced significantly when the NPIs are implemented.

The delay in the peak of the infections by an average of six months gives the ministry of health and the front-line health care workers more time to prepare for the fight against the pandemic by increasing the hospital beds with oxygen and ICU beds with ventilators.

The pandemic in Kenya has not yet shown exponential curve, thus most of the model parameters and assumptions on disease severity, derived from existing literature. Furthermore, there is not yet a consensus on the assumptions of fraction and infectiousness of asymptomatic in Kenya. The assumption that recovered individuals become immune remains unverified, and the model ignores demographic effects such as natural death.

\section{Conclusion}

The non-pharmaceutical interventions (NPIs) do work and provide ample time for healthcare system and healthcare workers preparedness. More death and hospital burden are averted by pandemic delay as a result of the NPIs. The model can be extended to include more features such as variation of susceptibility and randomness of the transmission rate.

\section{Abbreviations}

COVID-19; Coronavirus disease 2019, WHO; World Health Organization, SARS; Severe Acute Respiratory Syndrome, MERS-Cov; Korea Middle East Respiratory Syndrome Coronavirus, SEIR; Susceptible Exposed Infectious Recovery, R0; basic reproductive number.

\section{Declarations}

\section{Acknowledgments}

The authors appreciate ample time given by their respective universities towards this manuscript.

\section{Author's contributions}

All the authors contributed equally to this article. 


\section{Funding}

This study has not received any funding.

\section{Availability of data and materials}

Not Applicable.

\section{Ethics approval and consent to participate}

Not Applicable.

\section{Consent for publish}

Not Applicable.

\section{Competing interests}

The authors declare that they have no competing interests.

\section{References}

1. Li Q, et al. Early transmission dynamics in Wuhan, China, of novel coronavirus-infected pneumonia. N Engl J Med. 2020. doi:10.1056/NEJMoa2001316.

2. WHO (World Health Organization). "Statement on the meeting of the International Health Regulations (2005) Emergency Committee regarding the outbreak of novel coronavirus (2019-nCoV)," WHO Newsletter. 2020.

3. World Health Organization (WHO). "Novel Coronavirus (2019-nCoV) Situation Report - 121 January 2020," WHO Bull., 2020.

4. Gilbert M, et al. Preparedness and vulnerability of African countries against importations of COVID-19: a modelling study. Lancet. 2020. doi:10.1016/S0140-6736(20)30411-6.

5. Brand SPC, et al. Forecasting the scale of the COVID-19 epidemic in Kenya. medRxiv. 2020. doi:10.1101/2020.04.09.20059865.

6. Mizumoto K, Chowell G. Transmission potential of the novel coronavirus (COVID-19) onboard the diamond Princess Cruises Ship, 2020. Infect Dis Model. 2020. doi:10.1016/j.idm.2020.02.003.

7. Angeletti S, Benvenuto D, Bianchi M, Giovanetti M, Pascarella S, Ciccozzi M, “COVID-2019. The role of the nsp2 and nsp3 in its pathogenesis. J Med Virol. 2020. doi:10.1002/jmv.25719.

8. Kumar S, Poonam, Rathi B, "Coronavirus Disease. COVID-19: A New Threat to Public Health. Curr Top Med Chem. 2020. doi:10.2174/1568026620999200305144319. 
9. Cohen J, Kupferschmidt K. Strategies shift as coronavirus pandemic looms. Science (80-). 2020. doi:10.1126/science.367.6481.962.

10. Wynants $L$, et al. Prediction models for diagnosis and prognosis of covid-19 infection: Systematic review and critical appraisal. BMJ. 2020. doi:10.1136/bmj.m1328.

11. Tian S, et al. Characteristics of COVID-19 infection in Beijing. J Infect. 2020. doi:10.1016/j.jinf.2020.02.018.

12. Hu Z, et al. Clinical characteristics of 24 asymptomatic infections with COVID-19 screened among close contacts in Nanjing, China. Sci China Life Sci. 2020. doi:10.1007/s11427-020-1661-4.

13. Lin $\mathrm{C}$, et al. Asymptomatic novel coronavirus pneumonia patient outside Wuhan: The value of CT images in the course of the disease. Clin Imaging. 2020. doi:10.1016/j.clinimag.2020.02.008.

14. Bai Y, et al. Presumed Asymptomatic Carrier Transmission of COVID-19. JAMA - Journal of the American Medical Association. 2020. doi:10.1001/jama.2020.2565.

15. Singhal T. A Review of Coronavirus Disease-2019 (COVID-19). Indian J Pediatr. 2020. doi:10.1007/s12098-020-03263-6.

16. Yu KDS, Aviso KB. Modelling the Economic Impact and Ripple Effects of Disease Outbreaks. Process Integr Optim Sustain. 2020. doi:10.1007/s41660-020-00113-y.

17. Viner RM, et al. School closure and management practices during coronavirus outbreaks including COVID-19: a rapid systematic review. The Lancet Child Adolescent Health. 2020. doi:10.1016/S23524642(20)30095-X.

18. Jia Z, Lu Z. Modelling COVID-19 transmission: from data to intervention. Lancet Infect Dis. 2020. doi:10.1016/S1473-3099(20)30258-9.

19. Tuite AR, Fisman DN, Greer AL. Mathematical modelling of COVID-19 transmission and mitigation strategies in the population of Ontario, Canada. CMAJ. 2020. doi:10.1503/cmaj.200476.

20. Chowell G, Hengartner NW, Castillo-Chavez C, Fenimore PW, Hyman JM. The basic reproductive number of Ebola and the effects of public health measures: The cases of Congo and Uganda. J Theor Biol. 2004. doi:10.1016/j.jtbi.2004.03.006.

21. Delamater PL, Street EJ, Leslie TF, Yang YT, Jacobsen KH. Complexity of the basic reproduction number (R0). Emerg Infect Dis. 2019. doi:10.3201/eid2501.171901.

22. Stadler T, et al. Estimating the basic reproductive number from viral sequence data. Mol Biol Evol. 2012. doi:10.1093/molbev/msr217.

23. Anderson RM. Populations and Infectious Diseases: Ecology or Epidemiology? J Anim Ecol. 1991. doi:10.2307/5443.

24. May RM, Anderson RM. Population biology of infectious diseases: Part II. Nature. 1979. doi:10.1038/280455a0.

25. Anderson RM, May RM. Population biology of infectious diseases: Part I. Nature. 1979. doi:10.1038/280361a0.

26. Prem K, et al. The effect of control strategies to reduce social mixing on outcomes of the COVID-19 epidemic in Wuhan, China: a modelling study. Lancet Public Heal. 2020. doi:10.1016/S2468- 
2667(20)30073-6.

27. Martín-Calvo D, Aleta A, Pentland A, Moreno Y, Moro E, “Effectiveness of social distancing strategies for protecting a community from a pandemic with a data-driven contact network based on census and realworld mobility data," Https://Covid-19-Sds.Github./o/, 2020.

28. Chen H, Xu W, Paris C, Reeson A, Li X. Social distance and SARS memory: impact on the public awareness of 2019 novel coronavirus (COVID-19) outbreak. medRxiv. 2020.

doi:10.1101/2020.03.11.20033688.

29. Ferguson NM, et al. Impact of non-pharmaceutical interventions (NPIs) to reduce COVID-19 mortality and healthcare demand. ImperialAcUk. 2020. doi:10.25561/77482.

30. Eubank S, et al. Modelling disease outbreaks in realistic urban social networks RID D-7497-2011 RID A3421-2008. Nature. 2004. doi:10.1038/nature02541.

31. Butcher J. Runge-Kutta methods. Scholarpedia. 2007. doi:10.4249/scholarpedia.3147.

32. The Mathworks Inc., "MATLAB 2015 - MathWorks," 2016.

33. Shampine LF, Reichelt MW. The MATLAB ode suite. SIAM J Sci Comput. 1997. doi:10.1137/S1064827594276424.

34. Kenya National Bureau of Statistics. 2019 Kenya Population and Housing Census. 2019.

35. Mwalili S, Kimathi M, Ojiambo V, Gathungu D, Mbogo R. SEIR model for COVID-19 dynamics incorporating the environment and social distancing. BMC Res Notes. 2020. doi:10.1186/s13104-02005192-1.

\section{Figures}

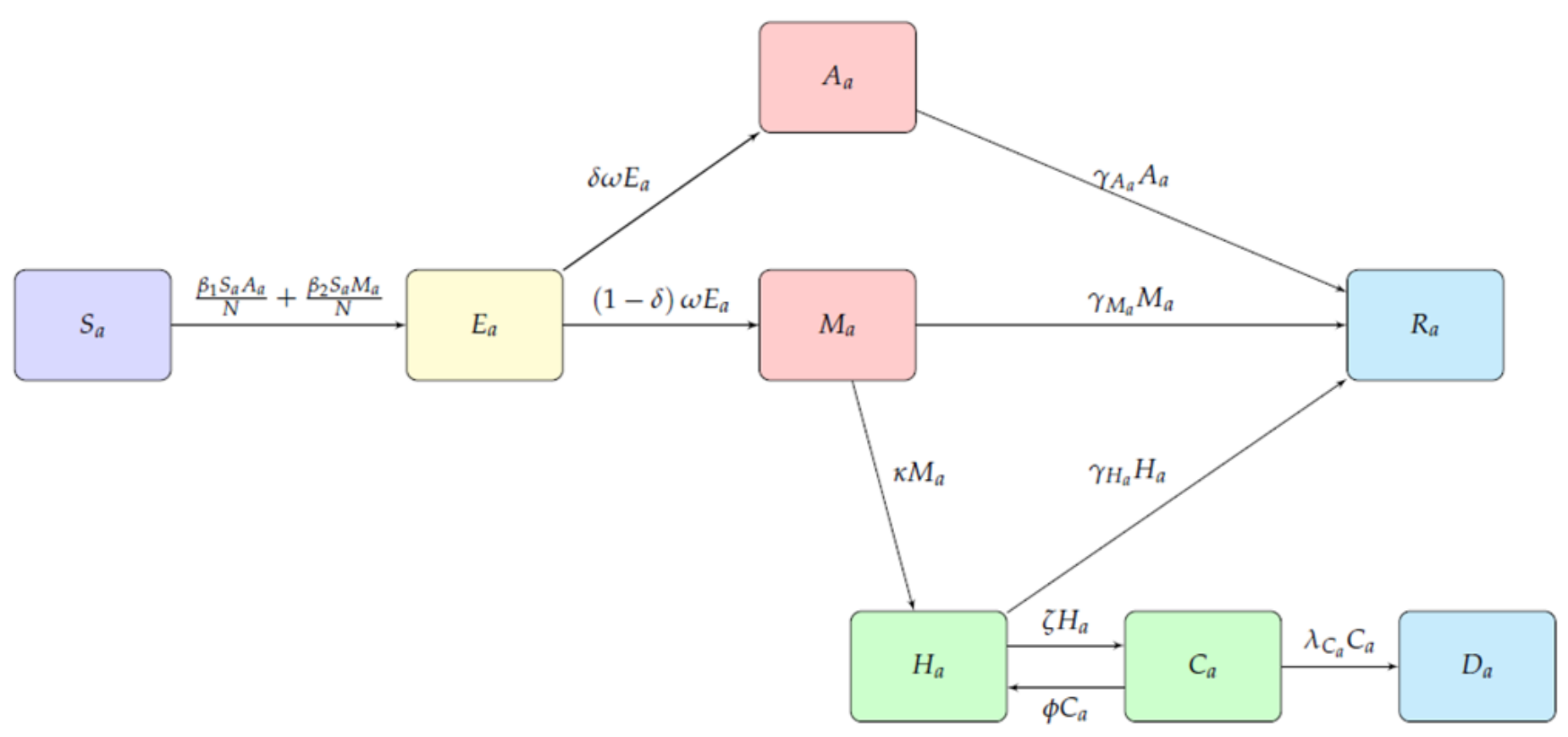

Figure 1 
A schematic illustration of the underlying model. S corresponds to the 'susceptible' population, E is 'exposed', A is 'asymptomatic infectious', $A$ is 'symptomatic infectious', $\mathrm{R}$ is 'recovered', $\mathrm{H}$ is 'severe' (hospitalized), $\mathrm{C}$ is 'critical in (ICU)' and D is 'dead'.

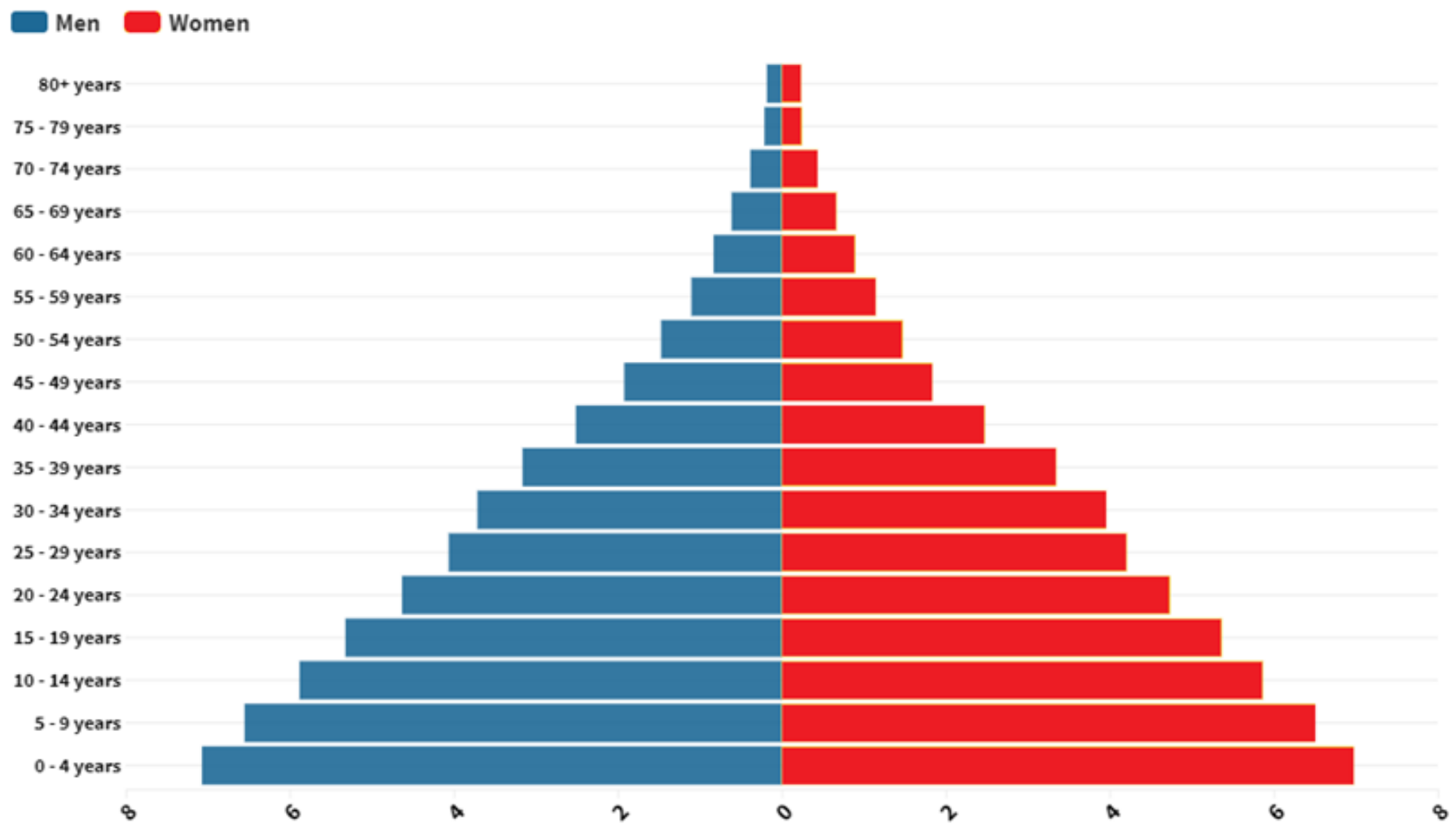

\section{Figure 2}

The age pyramid of the Kenyan population distribution by sex 

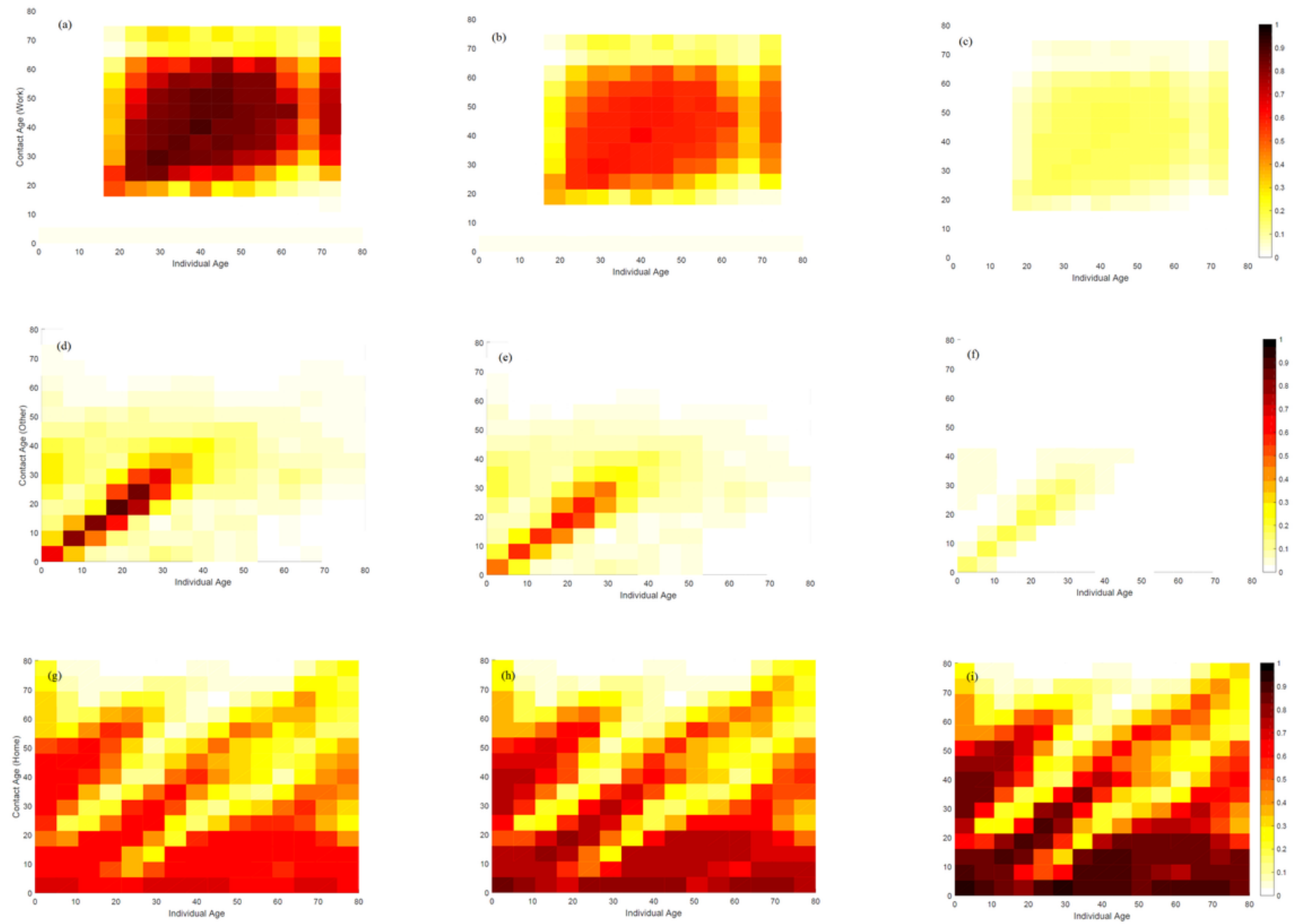

\section{Figure 3}

Contact matrices at with rows showing the home, other and work contacts, and column the three scenarios (column 1 is the unmitigated (UM), column 2 the $45 \%$ reduction (M45) and column 3 the school closure, curfew and partial lockdown (SCL)) 


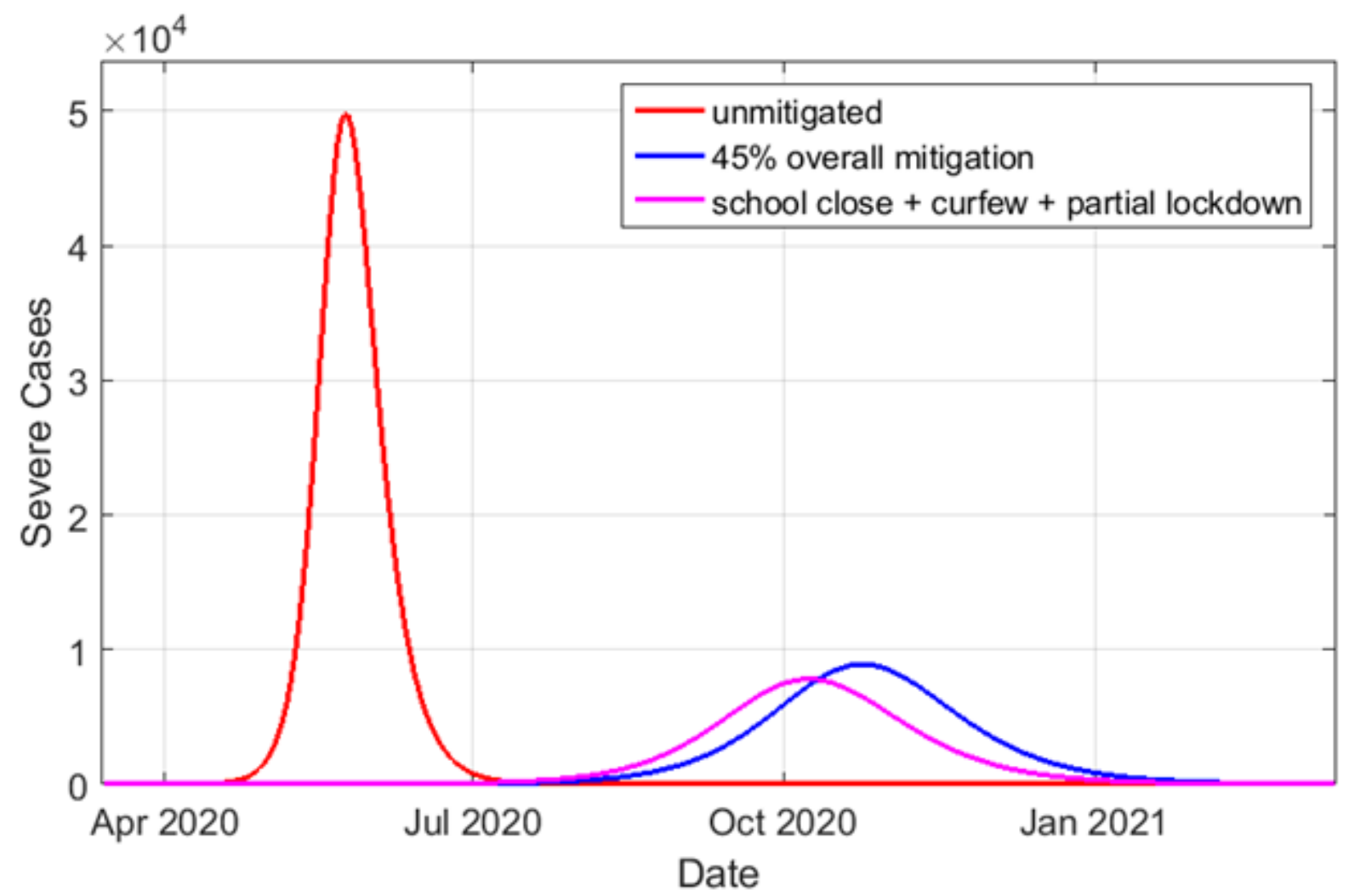

Figure 4

Number of Severe cases reported on day under unmitigated scenario (red), mitigation with eventual $45 \%$ reduction of all contacts (blue) and in magenta the mitigation with school closure $(100 \%$ reduction in school contacts) plus curfew (35\% in work and other contacts) plus partial lockdown ( $45 \%$ reduction in work and other contacts) with $25 \%$ increase in home contacts.

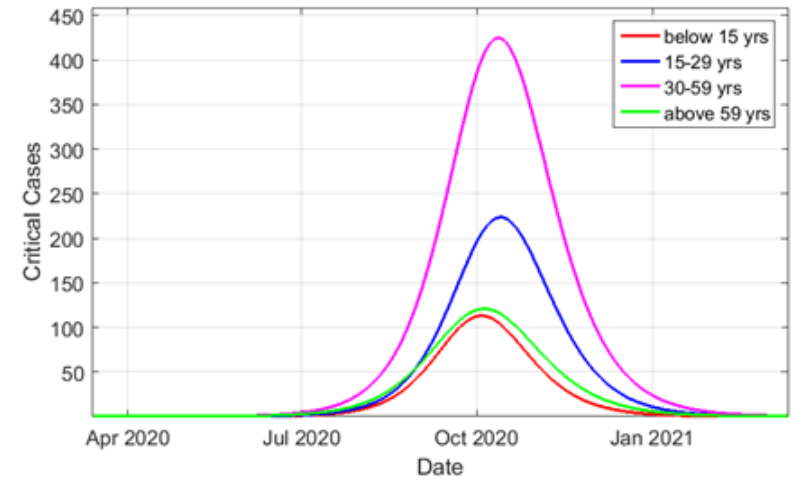

(a)

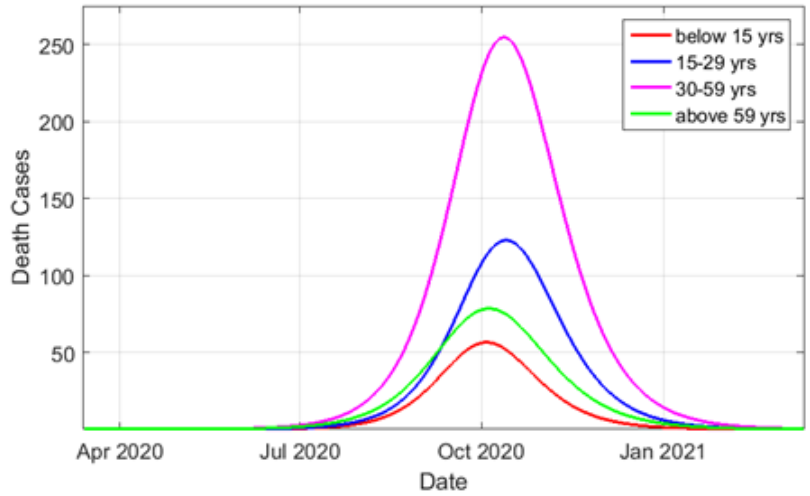

(b)

\section{Figure 5}

Number of critical cases (a) and deaths (b) reported by age under the school closure, curfew and partial lockdown non-pharmaceutical interventions 